\title{
Participatory planning and major infrastructure: experiences in REI NSIP regulation
}

\begin{abstract}
Planning for large-scale infrastructure is expected to enable public participation, including in decisions on major renewable-energy infrastructure (REI). This paper examines the UK's Nationally Significant Infrastructure Projects (NSIP) decision-making processes, which offer a particular arrangement of the representation and contributions of local people, with limited opportunities for dialogue. The study uses focus groups to provide insights into public experiences of involvement in REI NSIP regulation. Findings confirm that there is a need to go beyond statutory requirements to enable full and equitable access to decision making on large-scale developments, and shows the importance of considering how procedures operate for specific communities. They also indicate the importance of local understandings of power within the context of REI decision making, and ad hoc relational work of planners in 'non-dialogic' participatory contexts.
\end{abstract}

Keywords: participatory planning, major infrastructure, renewable energy, regulation, focus groups

\section{Introduction}

Planning processes for large-scale infrastructure are expected to enable public participation. Participatory planning and energy studies indicate that meaningful engagement is challenging. They have paid most attention to long-standing approaches to decision making on smaller scales of development, when new ways of involving local people in planning processes for larger developments continue to emerge. This paper examines one of these, the UK's Nationally Significant Infrastructure Projects (NSIP) regulatory regime. It studies the experiences of local community actors in renewable-energy infrastructure (REI) projects, which is of particular interest given current carbon reduction targets of the $\mathrm{UK}$, and questions around the scope for contestation in that context (Rydin et al., 2015).

This paper adds to existing literature with a study of public experiences of participation in decision making on large renewable energy offered by the relatively new NSIP system. Amongst the diverse contexts where publics participate in planning,

Lucy Natarajan is Researcher at the Bartlett School of Planning, UCL, Central House, I4 Upper Woburn Place, London, WCiH oNN; Simon J. Lock is Lecturer at the Department of Science \& Technology Studies, UCL, 22 Gordon Square, London, WGiE 6BT; Yvonne Rydin is Professor at the Bartlett School of Planning, UCL, Central House, I4 Upper Woburn Place, London, WGiH oNN. Maria Lee is Professor at the Faculty of Laws, UCL, Bentham House, 4 Endsleigh Gardens, London, WG.H oEG; email: lucy.natarajan@ucl.ac.uk; simon.lock@ucl.ac.uk; y.rydin@ucl.ac.uk; maria.lee@ucl.ac.uk. This article was published as open access under a CG BY license: https:// creativecommons.org/licenses/by/4.o. 
this is a critical field for studying the experience of local people, offering a particular arrangement of the representation and contributions of local people. As explained below, the new legal processes place authority for large infrastructure with central government, and local publics are entitled to be consulted and contribute evidence directly to regulatory examinations. Participation in this centralised decision-making system, backed up, moreover, with a strong policy presumption in favour of development, raises fresh questions around the presence of members of the public in, and their contributions to, planning processes.

In order to understand whether the new NSIP processes might enhance participation, we offer an evaluation of empirical data from a series of focus groups with local publics who participated in them. Since the establishment of the NSIP regulatory 'regime', there have been applications for a range of infrastructure (Morphet and Clifford, 2017), including large energy-generating station developments using renewable and low-carbon technologies. That REI is mainly wind turbines, with some using biomass, energy from waste and tidal lagoons. Through nine focus groups, using inductive analysis, this study provides insight into the experiences and views of participating publics.

The rest of this paper is as follows. First, the new participatory arrangements of the NSIP regime are set out. Next, the literature concerning the aspirations and challenges of public participation in planning is discussed, focusing on REI and largescale developments. Next, the methodology for the focus groups is introduced. In the following section, findings from the focus groups are presented under three themes that emerged from the analysis: fairness of procedures, status of evidence and levels of trust. The paper concludes with a discussion of the findings and implications for delivering on REI and participatory planning.

\section{New NSIP institutional arrangements}

The Planning Act 2008 (TSO, 2008) provided a new set of regulatory processes for planning and consenting major infrastructure in England and Wales, for 'nationally significant infrastructure projects' (NSIP). These were defined under the Act to include various major commercial, energy, transport, waste and water infrastructure, including offshore energy-generating stations with a capacity of over Ioo megawatts, and over fifty megawatts for those onshore. Decisions for onshore wind energy of ten megawatts have been removed from the NSIP system since the time of the study, the significance of which is discussed in the final section of this paper. The specific roles established in relation to the involvement of the public in the regulatory processes continue to apply to current NSIP.

Decisions on NSIP are taken by the relevant Secretary of State, who is advised by an examining authority (ExA). The ExA can be either an individual or a panel 
appointed by the Planning Inspectorate (PINS). Following a lengthy pre-application procedure, an application for development consent undergoes an examination lasting up to six months. The ExA produces a report from the examination with a recommendation for the Secretary of State on whether to grant consent.

An NSIP examination is different from public inquiries, which have been a key part of decision-making processes for major infrastructure in the UK (Toke, 2005; Marshall, 20I3; Ellis et al., 2009). It is designed to be inquisitorial (rather than adversarial), primarily written, and there is a presumption against cross-examination. Local people (and others) can register as interested parties by writing to the ExA with 'relevant representations'. They may then get involved in the examination, mainly through written submissions and documentary exchange, but also by speaking at hearings and accompanying the ExA on site visits. Documentary exchange is conducted via email and all material is made public on the PINS website, including the application and revisions to it; 'relevant representations'; questions from the ExA and responses to them from the applicant and other parties; statements of common ground between the applicant and other parties; audio records of hearings and maps of sites visited; and further representations and evidence submitted by interested parties and others, including statutory bodies. The last of these includes local-impact reports from local authorities, advice on environmental matters from statutory nature conservation bodies (Natural England and Natural Resources Wales), and typically also submissions from large organisations and businesses about their interests in the land or anticipated impacts of the proposed development. Hearings are organised for compulsory acquisition matters, specific issues (e.g. landscape and visual impacts), or general purposes (i.e. to cover a broader range of concerns). These are open to the public, and interested parties are amongst those who make representations. The ExA will determine the location and agenda for any site visit and may invite interested parties and others to accompany them, but must not interact with them.

NSIP processes provide for public participation in the pre-application stages. Prior to submitting an application for examination, there are various duties on the developer, including drafting a development-consent order and conducting an environmental assessment. The developer is also required to consult with statutory and non-statutory bodies, those with interests in the land, and the local community. The 2008 Act stipulates that the developer must consult with relevant local authorities on the processes for consultation with 'people living in the vicinity of the land' (Section $47(\mathrm{I})$ ). The pre-application consultation stages of NSIP processes allow many (though not all) issues to be resolved prior to the examination.

This system of deciding major infrastructure offers a very particular set of participatory arrangements. A complete comparison of the diverse alternative participatory channels within other major infrastructure decision-making systems is beyond the scope of this paper. The NSIP arrangements have two distinctive features when set 
aside from local planning processes that are the main subject of the literature on public involvement (see below). First, NSIP processes provide in principle for a high level of 'presence' of local people, who, in addition to being part of the pre-application consultations, may represent themselves directly in the regulatory examination, through the submission of written statements and other evidence (for instance photography and maps), and/or by making oral representations at hearings. Second, exchanges with local people in the NSIP processes are part of an inquisitorial process. It is rooted in questioning by ExAs and documentary exchange, which reduces the opportunities for dialogue and prioritises the provision of information over discussions of value. This paper asks whether and how the new institutional arrangements might or might not enhance public participation.

\section{Participation in regulatory planning processes for major REI}

This section discusses the literature on public participation in planning where 'ordinary' citizens are involved in decision-making processes, with a focus on regulatory contexts that seek to deliver development at scale, and renewable-energy infrastructure in particular. A robust body of work into REI has demonstrated the critical role of public views of decision-making procedures and concerns about public participation associated with expertise. These two areas are introduced and discussed with reference to the wider body of research on large-scale developments and local planning. Finally, the implications for participatory procedures, and expectations of public involvement in the regulatory REI context are considered. We note a central tension between the dialogic foundations of participatory planning and the position of participating lay publics in relation to power structures, whether socio-economic, political or related to 'expertise'.

\section{The public and procedures}

Current studies of REI, both smaller and larger projects, have a particular interest in public views on procedures. This derives from a focus on public attitudes towards renewable-energy development, most notably in studies of wind energy infrastructure, where a so-called 'social gap' exists (Bell et al., 2005; Bell et al., 2013) between national support for developing renewables and local resistance to REI projects. Research into that phenomenon (Bidwell, 2013; Hall et al., 2013) has concluded that local resistance to wind farm developments cannot be attributed to NIMBY-ism (attitude of 'not in my backyard'), or individually motivated protectionism of local space, but to values and beliefs. Those attitudes include psychosocial factors, e.g. place attachment (Devine-Wright, 20ı Ia; 201 Ib), and views on the fairness of decision making. Fairness for participating publics is defined not only in terms of 'development outcomes', 
e.g. the environmental and economic effects of wind farm developments and their likely distribution (Bidwell, 20I3; Brennan et al., 2017), but also in terms of procedural openness and inclusivity (Walker and Devine-Wright, 2008) and particularly in relation to how conflicting interests are managed (De Groot et al., 20I4; Hall et al., 2013). From this perspective, procedures ought to enable exchanges over the values that underpin conflict, including values associated with local places that might be impacted by development projects (Devine-Wright, 2013).

Research on participation in other planning contexts also suggests that public responses to processes are critical. They emphasise how interactions between authorities and the public can make or break trusting relationships. This builds on foundational works that proposed that public participation would connect individuals to wider society, because involvement in planning processes could engender trust and help build relationships between local people and public organisations. Public involvement was presented as a means to reworking the relationships between planners and local 'stakeholder' communities (Arnstein, I969; Aleshire, I970; Smith, I973) and rooted in an understanding of 'citizen' or 'public' participation in decision making as a basic entitlement (Johnson, I984). Studies continue to demonstrate how participation may foster relationships between state actors and citizens, particularly in local planning processes (Gallent and Robinson, 2012). However, some common difficulties in building trust are known to arise. Early communications with local people are helpful and delays in raising public awareness can undermine trust in planning authorities, as Upham and Shackley's study (2006) demonstrates. In addition, the length of time needed to build trust can be significant (Tait, 20I2), and mistrust is not uncommon both generally for planning (Tait, 2012) and more specifically during participation (Laurian, 2009). Further, Legacy has shown how speeding up and closing down decision-making procedures at the selection stage for major infrastructure project planning, even after deliberative strategy making, can undermine relationships with engaged communities and fuel antagonistic responses (Legacy et al., 2017).

\section{Expertise}

Concerns have been raised around the forces of expertise within planning for REI. It has been well argued that the dominance of expert knowledge results in epistemic conflict, particularly within participatory encounters. Discourse coalitions between powerful interests have been noted (Mander, 2008), and the tendency to privilege scientific approaches and discount lay knowledge has been seen both in environmental governance generally (Eden, I996; Eden et al., 2006) and in REI NSIPs specifically (Rydin et al., 20I8a; 20I8b). Indeed, in the context of major REI it is argued that both planners and local people are complicit in reinforcing the dichotomy between lay and expert knowledges (Aitken, 2009). 
The concern with expertise in REI runs parallel to a desire in environmental governance more generally to move away from the 'information deficit' view of citizens, as 'unknowing actors' outside government who need to be informed by experts (Owens, 2000). Studies of local planning provide further arguments against overreliance on expertise, since communities can introduce valuable lay knowledge to planning. Substantive learning has been evidenced in local planning (Lyhne et al., 2016; Natarajan, 2017), and non-technical expertise of local communities has also helped build more accurate maps in remote uncharted areas (Schuler et al., 2006), and better understand local ecology (Yli-Pelkonen and Kohl, 2005).

However, studies of local planning warn against naive assumptions about collaborations and argue that power must be addressed, since there will be conflicts between different interests (Purcell, 2009; McClymont, 20I I) and prior existing politics (Innes and Booher, 2004; Flyvbjerg, 1998) within any instance of participation. This is especially noted in contexts of 'economic neo-liberalism' where social concerns are easily subsumed by dominant private interests (Purcell, 2009). The concerns associated with surrounding power structures found in studies of local planning are more strongly stated in cases of large-scale development where the private sector partners with government. Research into the governance of mega-projects, for instance (Müller, 2015), demonstrates how community actors are sidelined. By and large the assessment is that 'pluralist' decision-making networks and investment vehicles reduce democratic and public accountability, as captured in Swyngedouw et al.'s (2002) study of major urban development projects undertaken in European city centres.

\section{Participatory procedures in planning}

As set out above, theoretical arguments have been made for the relational and epistemic benefits of involving local and lay actors in planning REI, and these are premised on procedures that can enable both exchanges over interests and their underpinning values, and the introduction of lay knowledge. This study is particularly concerned with a regulatory context where there are new statutory arrangements for participation. Studies of large-scale renewable-energy infrastructure have argued that the existence of procedural rights does not necessarily indicate that there will be useful exchanges (Lee et al., 2013), and that statutory procedural requirements do not necessarily ensure the provision of adequate participatory processes (Songsore et al., 2017). Indeed, a similar case is made in planning for small-scale developments, devolved to small neighbourhood authorities (Wargent and Parker, 2018). Thus the detail of participatory modes associated with statutory rights is likely to be critical. As noted above, the NSIP regulatory context offers high levels of presence for local people, through written and oral means of representation within the planning examination, but limits the opportunities for dialogue. 
The dialogic orthodoxy in participatory planning comes from foundational 'collaborative-planning' work (Forester, I999; Healey, I992; 2003; I997; Booher and Innes, 2002; Innes, I995), which made the case that procedures should be deliberative, such as face-to-face exchanges where relationship building and social learning may be promoted (Wenger, 2010; Holden, 2008). As noted, there are strong caveats to sole reliance on such modes because powerful interests (and their knowledge) may dominate (i.e. in addition to more fundamental theoretical challenges; see, for instance, Huxley and Yftachel (2000)). However, relying on rights is also not in itself enough. Just as expertise can dominate in formal environmental planning contexts, in spatial planning 'technocratic' approaches create difficulties in dealing with lay knowledge (Curry, 2012). 'Legalistic' approaches are expected to reduce planners' reflexivity (Wesselink et al., 20 I) and managerialist institutional and working cultures may further restrict what is discussed or considered (Fox-Rogers and Murphy, 2016). Thus the use of diverse formal and informal modes of public participation has been preferred over prescribed ones (Cornwall, 2008). In local planning a range of different techniques are noted, which Brody et al. (2003) list as including hearings, newspaper advertisements, public meetings, open discussions, posting to properties, newspaper inserts, public notices, announcements, dissemination of proposals, advisory committees and informal working sessions. As participatory activities grow, the work involved can be onerous to all involved (Baker et al., 2007) and lessen participation due to participation fatigue (Baker et al., 20I0). This can be exacerbated where practical barriers demotivate participants, i.e. as well as creating instances of exclusion (Walker et al., 2006).

In summary, current literature on REI and large-scale developments demonstrates the critical position of public views, and approaches to knowledge. Public views on procedures are important in REI literature, and participatory planning studies suggest that they should be understood as part of longer-term relations between the public and the machinery of the state. Concerns around the role of expertise are seen across studies of REI and local planning, in relation to the dominance of experts and those in positions of power. Procedural detail is critical to delivering 'meaningful' exchanges, and the efforts involved are likely to be substantial. Having set out the debates around substantial rights to involvement, this paper now moves on to evaluate the performance in the NSIP regime, drawing on lay actors' experiences.

\section{Methodology}

The empirical data used in this paper come from a series of nine qualitative focus groups involving sixty-nine participants, conducted across the UK, between 8 June and 24 November 20I6. The focus group is a technique for gathering data through small discursive group interviews, typically involving between five and twenty participants. 
The interview is conducted through a discussion that focuses on the particular issue in question, and is guided by a moderator who assumes a non-dominant position (see, for example, Barbour and Kitzinger, I998).

In contrast to formal or individual interview, where questioning can 'lead' and thus bound and encourage 'satisficing' in responses (Simon, 1978), moderated focus-group discussions enable the emergence of views that may be considered 'unacceptable' or transgressive. Focus groups are not designed to provide data that are statistically representative; instead their aim is to uncover meaning within specific contexts and help explain social situations. They enable research to explore experiences and attitudes in a way that other methods do not, as the encouragement of participant-led discussions allows unanticipated associations and meanings to arise spontaneously, which are a form of shared interpretive practice or 'communicative learning' (Petts, 2007). The exchanges within focus groups are therefore a source of insight into the ways in which social attitudes result from social interactions, rather than being formed in isolation. Participants in the focus groups for this paper were told they would be asked to speak about their experiences on a 'nationally significant infrastructure project' or NSIP case, but no further information was given in advance. In this way, we minimised any impact on the shape of the discussion of any pre-framed associations on the part of the researchers, and allowed for those issues most important to participants to come to the fore.

The cases discussed in the nine focus group events, with one event for each, were:

I Rampion Offshore Wind Farm

2 Walney Extension Offshore Wind Farm

3 Navitus Bay Offshore Wind Farm

4 Swansea Bay Tidal Lagoon

5 Brechfa Forest West Wind Farm

6 Burbo Bank Extension Offshore Wind Farm

7 Clocaenog Forest Wind Farm

8 Galloper Offshore Wind Farm

9 Thames Tideway Tunnel

This sample is a subset of cases selected in 2015 for a programme of research, which included eleven renewable-energy NSIP cases that had been through the system by the summer of 2015, plus Navitus Bay, which was added as the only declined case. The sample had seven offshore wind farms, two onshore wind farms, one biomass plant, one energy-from-waste plant, and one tidal lagoon. For a manageable number of events, eight cases were selected. A spread of locations and the declined case were included, and a control study case was added (case 9, a new waste-water infrastructure project in London) to test for effects that the focus on renewable energy might have. The sample therefore provides a strong set of renewable-energy cases, and a means to test for wider applicability of the findings. 
Focus-group participants share a relationship with the topic of focus (Kruger and Casey 2015). In this study, participants in each focus group had all participated in the same NSIP, and were selected to mirror the different types of local people who had been involved. The events brought together people who were in favour of the development going ahead, as well as those who opposed it or simply had concerns about it, and people registered as interested parties who were male and female, including residents, those with local businesses and representatives of a local group (as detailed in Table I). The local groups included local wildlife trusts, residents' associations, local amenity societies, sports and recreational societies, campaigning groups set up in response to an NSIP, civic societies, local nature and ecology conservation groups, and local wildlife interest groups.

Table 1 People participating in focus groups

\begin{tabular}{ll}
\hline Focus group participants by 'type' & $\#$ \\
Local resident (R) & 23 \\
Representing a local businesses (B) & 8 \\
Member of a local group (G) & 38 \\
\hline Men & 46 \\
Women & 23 \\
\hline
\end{tabular}

All participants volunteered on invitation, gave written informed consent to take part, and received a monetary incentive for their participation. The discussions lasted I20 minutes, and were moderated by a member of the research team, with a second member being present to ensure smooth operations. A semi-structured topic guide with a predecided list of topics was used as a starting point to open up and stimulate a wider, free-flowing discussion. Briefly, the topics were: getting involved, giving evidence, exchanges with others, influence and overall reflections on experiences. Focus groups are susceptible to influences of vocal participants (Stewart et al., 2007). While this can present practical problems, it mimics aspects of the social context, and the moderator encouraged each respondent to speak on each topic.

The focus groups were audio recorded, transcribed verbatim and analysed by two researchers in NVivo. Analysis was inductive and thematic, with careful reading of the data, code generation and identification of key themes. The codes were agreed by both researchers, and three overarching themes that related to the NSIP system emerged: fairness of procedures, status of lay evidence and levels of trust. In the report of findings that follows, all personal information is removed from quotations to ensure participant confidentiality, and only the NSIP in question (I to 9 from the list above) and type of respondent ( $\mathrm{R}, \mathrm{B}$ or $\mathrm{G}$ from the table above) are indicated. 


\section{Participating in NSIP planning processes}

\section{Fairness of procedures}

Following pre-application consultations conducted by prospective developers, there are two routes for members of the public to make representations at the regulatory examination of a 'nationally significant infrastructure project' or NSIP. As described in the 'New NSIP institutional arrangements' section above, local people could expect to engage either through written submissions or by speaking in person at a hearing. Examinations were primarily written, and local people tended to participate through developer consultations and written representations (Natarajan et al., 2018). However, given the emphasis on dialogue in participatory theory, and the importance of hearings in the construction of evidence (Rydin et al., 2018a; 2018b), oral representations might be expected to be particularly valuable. Local people participated via both routes, submitting written representations and attending hearings, which suggests a readiness to get involved. However, there were strong accounts of specific difficulties experienced in focus-group discussions of procedures, which were framed as 'unfair'.

To begin with in-person participation, people reported difficulties with access, in terms of either location or timing. Locations were typically described as inconvenient, and sometimes intentionally so. As one participant put it, 'they hold the meetings in the deep cellar somewhere, you know it's like a nuclear bunker [laughter], where nobody can find it' (6G). The scheduling of events during working hours was a notable barrier to engagement, and occasional rescheduling, sometimes at very short notice, further reduced the chances of people attending those events:

The dates of the hearings were confirmed very late and then they were changed at the last minute ... So even if someone had actually booked the day off, they wouldn't have been able to appear. $(3 \mathrm{R})$

The location and timing issues may have been particular to the context of participation in an NSIP case; nonetheless they affected the perceived fairness of procedures. One of the difficulties in interpreting focus group participants' comments was that some people did not distinguish between hearings and pre-application events. However, given the wide stakeholder community and possible attendees from different localities, it may have been unavoidable that a venue selected would be hard to access for at least some of the parties. In any case, the selection of the venue could be seen as disadvantaging particular localities more than others. In addition, given the limited timeframe for the examination there was an inevitable restriction on how much flexibility could be built into the timetabling of hearings. However, time-poor cohorts would be more likely to be inconvenienced in terms of access, and those in full-time employment particularly so. 
Nonetheless, local people did access NSIP events. Regarding experiences of hearings, the focus groups indicated that the formality of the settings could be a barrier to participation. People described how difficult they had found making oral representations, and how ExAs had facilitated with reassurances. One person recalled:

I had a mental block after about 30 seconds which was horrible ... [name of ExA panel member] very kindly said 'Don't panic. Come back to it.' ... and fortunately, those few seconds made all the difference. I was able then to get on. $\left({ }_{3} \mathrm{~B}\right)$

The professionalised set-up of examinations was particularly difficult for people who were unfamiliar with presenting in public. A typical description was, 'I'd never been to anything like that before but coming in from completely cold from the outside I found it very hostile' ( $\mathrm{IG})$. This finding is in line with studies of local planning where more informal settings have helped to increase levels of participation (Brody et al., 2003), and studies of other regulatory contexts where professional manners have reduced participants' confidence in engaging (Fitzpatrick and Sinclair, 2003). In the NSIP context the set-up of the room was a further challenge, as it was laid out for ExAs to hear evidence from different parties:

The layout of the room is not conducive to an inclusive hearing, is it? Because she is sitting on the top table with a couple of people each side of her and then down each side the proposers and the Local Council. And the opposition is spread out in seats at the back. We weren't part of the hearing. We were kind of an audience of the hearing. $(7 \mathrm{G})$

Turning to consider participation through documentary exchange, this could involve the use of e-mail and a PINS website, as noted in 'New NSIP institutional arrangements' above. In the focus-group discussions, the reliance on digital channels of communication was a particular concern. It was acknowledged that e-mail and websites could be an aid, but there were detailed discussions of how people had struggled with them. It was strongly argued that not all interested parties would be able to use the online resources, and a wider range of communication methods was needed. As one person put it, 'An effective communication strategy would use a number of strands to get to people ... there is overreliance on e-comms [Internet] and that is the problem' ( $\mathrm{I} G$ ). Groups who did not use the Internet were particularly affected, and most notably fishermen in examinations of offshore wind farms. However, even those who were IT-literate, and used the Internet regularly, reported that the digital mode was challenging, and particularly so given the great volumes of documentation and changing information involved. High download capacities were needed, but were not always at the disposal of interested parties. This tended to affect those in more rural areas, such as remote locations in Wales where onshore wind farms were proposed: 
that document may be so large that it takes your download [allowance] because we all struggle with broadband in this area. It might take your download [allowance] for the whole week and you can't get anything else for the rest of the week ... $\left({ }_{5} R\right)$

There was significant pressure on the NSIP participants during the examination, and it was commonly noted that this stage of involvement came after a lengthy period of earlier engagement with the developer. The upper limit of six months for the examination limited the time available to deal with the large volumes of evidence being presented (compounded by difficulties of accessing documentation). Focus-group discussions emphasised that a lay public needed more time to digest information and respond fully. In the words of one participant, 'We just didn't have time to consider it. It was just information overload' $(2 \mathrm{G})$. At the same time, the overall length of the processes was burdensome. People reported that the NSIP experience was tiring, as have participants in other regulatory regimes (Fitzpatrick and Sinclair, 2003). The levels of fatigue reported here were extreme (see the quote below), due to the combined intensity and duration of interactions. These levels are more commonly seen in ongoing and multiple participatory exchanges within the context of local governance (Bickerstaff and Walker, 2005):

But you feel really much worn down by the process. I welcomed the opportunity to talk to the developer or discuss things but it was just the way it went on and on and on... $(2 \mathrm{G})$

Fairness of procedures was a dominant theme in the focus groups' discussions of NSIP experience. As the points above demonstrate, certain people experienced particular communicative burdens. The location, timing and format of the opportunities for in-person participation had created frustration for those wishing to make oral representations during the examination. Moreover, the barriers were unfair as they would only be experienced by certain groups. Those with lower download capacity struggled more than others to access information; those with low levels of literacy or digital skills were less able to engage in documentary exchange; those without publicspeaking experience were more nervous in their oral representations; those without private transport were more challenged by locations of hearings; and those in fulltime employment were more strained by ad hoc scheduling of hearings. Overall, such procedural difficulties, and perceived unfairness, added to the intensity of the effort of getting involved in the NSIP examination for lay participants, who had typically also been involved over a significant period of time beforehand. However, overwhelmingly people stated that they would participate again in future, and offered two types of explanation. They would get involved because of direct effects of developments on themselves and/or their locality or, as summed up by one resident, 'because I'm a resident and it affects me and my home's everything to me' (8R). In addition, the attitudes of the ExAs towards local people had a strong effect on trust. Despite 
perceptions of 'unfair' procedures, people reported positive evaluations of exchanges with the ExA. The following extract is taken from a focus group who were reflecting on how hard it had been to access a hearing.

We did feel we got a very fair hearing, something we didn't actually expect, we were not even going to give any evidence really. (6Ga) I agree on that with you actually. $\mathrm{He}$ was very thorough and he did go through all the evidence that we presented. (6Gb)

\section{Status of lay evidence}

For participants in NSIP cases there is a tacit expectation that lay forms of evidence will be considered in parity with expert knowledge forms, since local people can make representations directly alongside professionals and government actors and question others' evidence. The analysis of the focus group data suggests that NSIP participants experience certain limits to their contributions, which shapes their views of the status of lay evidence. The analysis confirmed that evidence had been submitted and lay knowledges, such as written information from personal diaries or oral accounts of 'place' experience, had been heard. However, local people discussed in depth the limits to their input to the examination, how the substance of ExA considerations had been restricted, and their concerns about what they were unable to contribute.

Focus-group participants reported strong frustration with not being able to bring issues that they felt were basic and important into the ExAs considerations. These mainly related to the appropriateness of renewable-energy technology and local energy development contexts. In the NSIP regime the possible substance of discussions was limited because of the legal and policy context for decision-making endeavours to remove certain considerations of principle from examination (Rydin et al., 20I5). Local people were acutely aware of these boundaries and in focus-group discussions the idea that matters of principle could not be brought into examination was seen as highly problematic, as it put the key concerns of certain local groups 'off limits'. Some people had wanted to discuss whether renewable energy was appropriate, to argue either for or against it:

the positive benefits of the scheme and the negative benefits of not proceeding with the scheme were not considered by the Inspectorate. And that was an issue that we raised, and which we were denied the opportunity to bring forward. $\left.{ }_{3} \mathrm{G}\right)$

Others wished to consider planning policy and decisions, which they saw as related to the proposed NSIP being examined. They characterised evidence in the examination as 'isolated' from knowledge of related matters. For instance, a local person who wished to discuss the implications of other development applications in a local area said: 
There's very little knitting together of different applications. They onlylook at one in isolation and they wouldn't consider the one that's right next door and how they interact ... $\left({ }_{5} \mathrm{R}\right)$ That's right. $\left(5^{\mathrm{G}}\right)$

Focus-group discussions also highlighted an expert-lay divide in two ways. First, the technical nature of NSIP material, and the significant additional effort required for non-experts to engage with it. The use of formalised and expert languages is known to diminish trust (Talvitie, 20I I) and reduce engagement (Baker et al., 20Io) for lay actors. Here, the use of legal terminology was a particular concern because it reduced interested parties' understandings of others' evidence. A typical comment was, 'the gobbledegook and the language were so complicated, I think it would have put most people off getting involved. You needed to be a Philadelphia lawyer [i.e. exceptionally competent] just to understand it' ( $\left.{ }_{2} \mathrm{R}\right)$.

Second, there was a clear practical divide between expert and lay participants. Focus-group participants typically discussed the onerous volume of materials that were required in order to consider the issues within the NSIP examinations. For example, one person commented, 'Have you seen how much stuff there is to read? I mean, you need a lifetime to sit there and read it all' $(4 \mathrm{G})$. Discussions demonstrated just how extraordinary the volume of material and how unrealistic the work involved was for lay actors, in terms of reading through the application materials, or even just keeping track of some elements. People generally characterised this situation as comical or depressing:

I've got to say that's the most frightening set of books I think I've ever seen in my life.

Did you see the application documents? It must be about nine or ten volumes and they are about [gesturing with hand to indicate a large pile, and laughing]. (6G)

People who represented local groups consistently pointed out that it was particularly troublesome for them that information continued to be reworked through the period of the examination. Each change would need to be communicated to their members and the responses of the group deliberated in order to represent a collective view within the exam. The level of ongoing updates required throughout the NSIP processes became too great a burden for smaller local groups or those with lower resourcing. As one group representative noted, 'as time went by and they changed the thing round ... we didn't have the money to keep going back' ( $\left.{ }_{3} \mathrm{G}\right)$.

In summary, public participants in the examination perceived epistemic and practical barriers. The scale of technical work, and legal codification, added to the work of lay participants. Earlier studies have shown how expert and professional knowledge forms dominate ExAs' reasoning (Rydin et al., 20r8a). By contrast, the concerns reported here related more to the legal and practical limits to what would be discussed. 


\section{Levels of trust}

Open processes should, as discussed under 'Participation in regulatory planning processes for major REI' above, enhance levels of confidence and trust in the statutory processes. Clearly, NSIP examinations were 'open' as events were public, and all evidence was online, although (see 'Fairness of procedures' and 'Status of lay evidence' above) barriers to access were experienced by some people and there were limits to public understanding, which affected levels of confidence at certain points. However, the overall levels of trust in NSIP processes appeared to be mainly related to the position of the applicant or prospective developer.

Analysis of the focus-group data showed a strong and consistent perception that the NSIP processes privileged the involvement of the applicant. The strength of applicants' position within the NSIP processes shaped interested parties' trust in the decision-making processes, and this was true irrespective of local people's views on the development or individual interests. As one participant put it, 'I just feel there is one law for them and one law for us' $(2 \mathrm{R})$. This was manifest in a variety of ways. Most notably, communities were very aware that prospective developers' resources were much greater than their own, as this quote demonstrates:

If you spend all day writing the best email you've ever written to them, rest assured there's probably about fifteen people sitting in an office, who will be far better versed in the subject, who will be far better equipped, who have got far more money to spend ... a much better reply to you. $(2 \mathrm{~B})$

Applicants were also perceived as able to 'game' the system. Most commonly, people stated that developers took advantage of the processes and complex material to obfuscate evidence. In the words of one person, evidence was 'always written in a way that contradicts itself ... and if you actually want to find out what they're hiding its usually hidden under another title' (8R). Prospective developers also appeared to be granted significant leeway in the substance of their applications, which raised local people's suspicions about the overall processes. It has been pointed out that allowing developers 'flexibility' in the level of detail offered within consenting processes can be beneficial, for instance where it enables later innovative measures to help mitigate impacts, with the caveat that this relies on public confidence in NSIP decision making (Morphet and Clifford, 20I7). However, as the following quote demonstrates, people in the focus groups were taken aback at the low level of specification of technical detail and lack of grid connection elements allowed in NSIP processes:

Even when this original scheme was submitted it was somewhere between I94 and I2I turbines. Well, if a developer on land says 'I want to build a development between I94 and a I2I houses', then we'd say 'well, you've got to know exactly what you're going to do before we consider it'. So, it seems to me that the flexibilities are loaded in their favour. $\left({ }_{3} R\right)$ 
Levels of trust amongst local people were reduced by the strong position of the applicant within the NSIP processes. The criticisms of the strength of the applicants' position were mainly raised by those who had opposed consented developments. In addition, some people had raised concerns about the effect of developments on the value of their own property. 'These are massive multimillion-pound projects and, no disrespect to his lovely house, that could be paid off and other people's who are badly affected, for peanuts [i.e. at little cost]' $\left({ }_{7} \mathrm{R}\right)$. However, the observed power of prospective developers (for instance in their capacity to detail volumes of information) within the NSIP processes also affected levels trust amongst both supporters and opponents of developments in cases that were not consented. For example, people noted their concern that the applicant who was refused consent had not needed to consider the impacts on radar at a local airport.

Similarly, those who had supported a development emphasised that developers had put a lot of resources into pre-application consultations and public communications during the examination. They recognised the power that was inherent in this:

We supported it from the start before it came into the planning process ... and we were amazed by their public-relations machine ... and in fact in the end, it was so good, it made us a bit suspicious. $(4 \mathrm{G})$

Interested parties continued to worry about the position of the developer even after mitigation measures or protective changes to the proposed development were decided in the examination. They repeatedly questioned whether the developer would implement the protections that had been secured in the consent order. For example, one person stated, 'I won't know whether I was successful in my objective until after the project is complete' (8R). Others reported having continued to track the NSIP postconsent, to see whether conditions were complied with, and were wary of changes, as shown in the following quote:

And it seems they can just change the plans arbitrarily. So they've changed where the access tracks will be in the forest, the way that will go ... they changed the transport management plans and this is pointed out. This is not what [the ExA] consented at the [examination] but they are allowed to get away with it. Now why is that? $\left.{ }_{5} \mathrm{R}\right)$

To summarise, the developers were seen as extremely powerful, well-resourced actors, and it was observed that the applicants' behaviours within the NSIP processes could reduce levels of trust not only in the developer, but in the decision-making processes and ongoing governance of the NSIP. As a result, the NSIP decisions were said to be a 'done deal', and public involvement began to feel like a token. As one person put it: 'Well, the whole thing felt like a fait accompli actually ... there wasn't really a consultation process, there was an information process' (6G). 


\section{Conclusion}

This paper set out to look at how the NSIP arrangements for involving the public might deliver on expectations of participation in planning. As set out in the 'New NSIP institutional arrangements' section above, the new processes provide the means for a high level of presence of local people within decision making, via contributions to an inquisitorial-style regulatory examination, but with limited opportunity for dialogue. The decision making on renewable-energy infrastructure or REI cases was of particular interest given state policy goals of transitioning to renewable-energy generation. This section reflected on key findings from the study related to public involvement in planning and the NSIP regulation specifically. It then considered the importance of local understandings of power in context and the implications for the delivery of REI. Finally, it presented conclusions on participatory planning in the face of public engagement in 'non-dialogic' contexts.

The findings from this study demonstrate the importance of how statutory rights are put into operation. Certain communities and social groups needed to make extra efforts to engage in NSIP decision making. Opportunities for presence were not equally available to all local people. In particular, those who are time-poor suffer most, e.g. when there is ad hoc rescheduling of hearing. This echoes long-standing concerns of planning literature about access being restricted to only 'parts' of the local community. More unexpectedly, the practical barriers to lay contributions were as critical as epistemic ones. Earlier studies have focused on how lay knowledges are excluded by cultures of expertise (Rydin et al., 2018a; Rydin et al., 2018b). Here, the great volumes of documentation, including iterations of revisions, commonly formed a barrier to the contributions of lay actors, which was especially burdensome for local groups who needed to liaise with their members. Low levels of Internet capacity in rural areas and literacy amongst fishermen were a further barrier. This confirms the need to look beyond the existence of rights (Lee et al., 2013), and shows the importance of considering how procedures operate for specific communities. These challenges of access were found in decision making on large-scale developments but could apply to other planning matters. The ad hoc relational work of planners around the delivery of NSIP participatory procedures built trust and significantly improved the involvement of the public and facilitated lay contributions. The value of such good practice needs to be more widely recognised, encouraged and shared across the NSIP system and beyond.

The findings also draw attention to local understandings of power in context. Perceived procedural unfairness builds up to a greater sense of injustice, which will be problematic for the project of getting renewable-energy infrastructure built and accepted. When local communities feel that their concerns are not being given fair consideration, the local resistance to REI (Bell et al., 20I3; Bell et al., 2005) found in 
earlier studies may continue post-consent. Participants' concerns are also of interest to systems of REI decision making as they can undermine legitimacy. This is demonstrated by recent decentralising changes to the NSIP regime, where decisions on onshore wind energy projects in England and Wales with a generating capacity of at least ten megawatts have been devolved respectively to local planning authorities and the Welsh government. The present study suggests that participants observed developers to be empowered by the NSIP processes, being both aligned with policy goals and well equipped to deal with the procedures. Such observations fed into the perception that evidentiary processes intentionally privileged applicants.

Finally, this study has implications for public participation in non-dialogic participatory contexts. Studies of dialogic participatory processes show how powerful actors are enabled (e.g. Purcell, 2009) and communities excluded post-strategy-making in discussions on projects (e.g. Legacy et al., 20I7). Here the regulatory context includes communities in discussions on projects and restricts the topics and format of exchanges, yet the developer is still seen to benefit. The public continues to seek dialogue, e.g. in discussions over principle; however, the planning processes cannot adapt to accommodate this. Instead lay actors must adapt their expectations and modes of communication. This requires high levels of capital amongst communities, so that resources and social ties are not worn out by the extra efforts required. This suggests that in non-dialogic contexts of participation, certainly where professionalised forms of expert knowledge are privileged, more wealthy and established communities will fare better than others. It is notable that planners' interventions can offset some practical barriers, in terms of both access and forms of contribution, by providing a type of 'procedural advocacy'. ExAs responded to participants in the instances reported here, which constituted social (although not 'dialogic') interaction, thus taking up one aspect of the 'advocacy-planning' role proposed by Davidoff (I965) in assisting in the presentation of alternatives. No doubt further research will be needed to test the value of such relational work in other contexts, but it certainly helped build trust in NSIP regulation despite wider concerns about the powerful position of REI developers.

\section{Acknowledgement}

This paper was supported by ESRC funding (Award number i64522).

\section{References}

AITKEN, M. (2009), 'Wind power planning controversies and the construction of "expert" and

"lay" knowledges', Science as Culture, 18, 47-64.

ALESHIRE, R. A. (I970), 'Costs, benefits and approaches', Urban Affairs Quarterly, 5, 369-93. 
ARNSTEIn, S. R. (I969), 'A ladder of citizen participation', Fournal of the American Institute of Planners, 35, 2I6-24.

BAKER, M., COAFFEE, J. and SHERRIFF, G. (2007), 'Achieving successful participation in the new UK spatial planning system', Planning Practice E Research, 22, 79-93.

BAKER, M., HINCKS, S. and SHERRIFF, G. (20I0), 'Getting involved in plan making: participation and stakeholder involvement in local and regional spatial strategies in England', Environment and Planning C: Government and Policy, 28, 574-94.

BARbour, R. and Kitzinger, J. (1998), Developing Focus Group Research: Politics Theory and Practice, London, Sage Publications.

BELL, D., GRAY, T. and HAGGETT, C. (2005), "The "social gap" in wind farm siting decisions: explanations and policy responses', Environmental Politics, I4, 460-77.

BELL, D., GRAY, T., HAGGETT, C. and SWAFFIELD, J. (20I3), 'Re-visiting the "social gap": public opinion and relations of power in the local politics of wind energy', Environmental Politics, 22, II $5-35$.

BICKERSTAFF, K. and WALKER, G. (2005), 'Shared visions, unholy alliances: power, governance and deliberative processes in local transport planning', Urban Studies, 42, 2I23-44.

BIDWELL, D. (2013), 'The role of values in public beliefs and attitudes towards commercial wind energy', Energy Policy, 58, i89-99.

BOOHER, D. E. and INNES, J. E. (2002), 'Network power in collaborative planning', fournal of Planning Education and Research, 21, 22 I-36.

BRENNAN, N., VAN RENSBURG, T. M. and MORRIS, C. (20I7), 'Public acceptance of large-scale wind energy generation for export from Ireland to the UK: evidence from Ireland', fournal of Environmental Planning and Management, 6o, 1967-92.

BRODY, S. D., GODSCHALK, D. R. and BURBY, R. J. (2003), 'Mandating citizen participation in plan making: six strategic planning choices', Journal of the American Planning Association, 69, $245^{-64}$.

CORNWALL, A. (2008), 'Unpacking “participation” models, meanings and practices', Community Development fournal, 43, 269-83.

CURRY, N. (2012), 'Community participation in spatial planning: exploring relationships between professional and lay stakeholders', Local Government Studies, 38, 345-66.

DAVIDOFF, P. (I965), 'Advocacy and pluralism in planning', Journal of the American Institute of

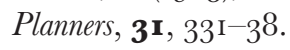

DE GROOT, J., CAMPBELl, M., ASHLEY, M. and RODWELL, L. (20I4), 'Investigating the co-existence of fisheries and offshore renewable energy in the UK: identification of a mitigation agenda for fishing effort displacement', Ocean and Coastal Management, ro2, 7-I8.

DEVINE-WRIGHT, P. (2OI Ia), 'Enhancing local distinctiveness fosters public acceptance of tidal energy: a UK case study', Energy Policy, 39, 83-93.

DEVINE-WRIGHT, P. (201 Ib), 'Place attachment and public acceptance of renewable energy: a tidal energy case study', Journal of Environmental Psychology, 3i , 336-43.

DEVINE-WRIGHT, P. (2013), 'Think global, act local? The relevance of place attachments and place identities in a climate changed world', Global Environmental Change, 23, 6r-69.

EDEN, S. (I996), 'Public participation in environmental policy: considering scientific, counterscientific and non-scientific contribution', Public Understanding of Science, 5, I83-204. 
EDEN, S., DONALDSON, A. and WALKER, G. (2006), 'Green groups and grey areas: scientific boundary-work, nongovernmental organisations, and environmental knowledge', Environment and Planning $A, \mathbf{3 8}$, Iо6 $\mathrm{I}-76$.

ELlis, G., COWELl, R. J. W., WARREN, C., STRACHAN, P., SZARKA, J., HADWIN, R., MINER, P., WOLSINK, M. and NADAÏ, A. (2009), 'Wind power: is there a "planning problem”?', Planning Theory \& Practice, I0, $52 \mathrm{I}-47$.

FITZPATRICK, P. and SINCLAIR, A. J. (2003), 'Learning through public involvement in environmental assessment hearings', fournal of Environmental Management, 67, I6I-74.

Flyvbjerg, B. (1998), Rationality and Power: Democracy in Practice, Chicago, The University of Chicago Press.

FORester, J. (1999), The Deliberative Practitioner: Encouraging Participatory Planning Processes, Cambridge, MA, MIT.

FOX-ROGERS, L. and MURPHY, E. (20I6), 'Self-perceptions of the role of the planner', Environment and Planning B: Planning and Design, 43, 74-92.

Gallent, N. and ROBInsOn, S. (2012), Neighbourhood Planning: Communities, Networks and Governance, Bristol, Policy Press.

HALL, N., ASHWORTH, P. and DEVINE-WRIGHT, P. (20I3), 'Societal acceptance of wind farms: analysis of four common themes across Australian case studies', Energy Policy, 58, 200-8.

HEALEY, P. (1992), 'Planning through debate: the communicative turn in planning theory', Town Planning Review, 63, I43-62.

HEALEy, P. (1997), Collaborative Planning: Shaping Places in Fragmented Societies, Basingstoke, Palgrave McMillan.

HEALEY, P. (2003), 'Collaborative planning in perspective', Planning Theory, 2, IOI-23.

HOLDEN, M. (2008), 'Social learning in planning: Seattle's sustainable development codebooks', Progress in Planning, 69, $\mathrm{I}-40$.

HUXLEY, M. and YIFTACHEL, O. (2000), 'New paradigm or old myopia? Unsettling the communicative turn in planning theory', Fournal of Planning Education and Research, $\mathbf{1 9}, 333-42$.

INNES, J. E. (I995), 'Planning theory's emerging paradigm: communicative action and interactive practice', Fournal of Planning Education and Research, $\mathbf{1 4}$, I83-89.

INNES, J. E. and BOOHER, D. E. (2004), 'Reframing public participation: strategies for the 2Ist century', Planning Theory \& Practice, 5, 419-36.

JOHNSON, W. C. (I984), 'Citizen participation in local planning in the UK and USA: a comparative study', Progress in Planning, 21, I49-22I.

Kruger, R. A. and CASey, M. A. (2015), Focus Groups: A Practical Guide for Applied Research, Thousand Oaks, CA, Sage Publications.

LAURIAN, L. (2009), 'Trust in planning: theoretical and practical considerations for participatory and deliberative planning', Planning Theory E Practice, ro, 369-9I.

LEE, M., ARMENI, G., DE GENDRA, J., CHAYTOR, S., LOCK, S. J., MASLIN, M., REDGWELL, G. and RYDIN, Y. (20I3), 'Public participation and climate change infrastructure', fournal of Environmental Law, 25, 33-62.

LEGACY, C., CURTIS, C. and SCHEURER, J. (2017), 'Planning transport infrastructure: examining the politics of transport planning in Melbourne, Sydney and Perth', Urban Policy and Research, 35, 44-6o. 
LYHNE, I., NIELSEN, H. and AAEN, S. B. (2016), 'What determines the substantive influence of public participation? An investigation of planners' views on conditions for participatory practices in Denmark', Planning Practice E Research, 31, 31 I-26.

McCLYMONT, K. (201I), 'Revitalising the political: development control and agonism in planning practice', Planning Theory, ro, 239-56.

MANDER, S. (2008), 'The role of discourse coalitions in planning for renewable energy: a case study of wind-energy deployment', Environment and Planning C: Government and Policy, 26, 583-6oo.

MARSHALL, T. (2013), 'The remodeling of decision making on major infrastructure in Britain', Planning Practice \& Research, 28, I22-40.

MORPhet, J. and CLIFFORD, B. (2017), Infrastructure Delivery: The DCO Process in Context (Main Report), London, NIPA.

MÜLLER, M. (2015), 'The mega-event syndrome: why so much goes wrong in mega-event planning and what to do about it', Journal of the American Planning Association, 81, 6-17.

NATARAJAN, L. (20I7), 'Socio-spatial learning: a case study of community knowledge in participatory spatial planning', Progress in Planning, I I I, I-23.

NATARAJAN, L., RYDIN, Y., LOCK, S.J. and LEE, M. (2018), 'Navigating the participatory processes of renewable energy infrastructure regulation: a "local participant perspective" on the NSIPs regime in England and Wales', Energy Policy, r I4, 20 I-Io.

OWENS, S. (2000), "Engaging the public": information and deliberation in environmental policy', Environment and Planning A, 32, I I4I-48.

PETTS, J. (2007), 'Learning about learning: lessons from public engagement and deliberation on urban river restoration', Geographical fournal, 173, 300-I I.

PURCELL, M. (2009), 'Resisting neoliberalization: communicative planning or counter-hegemonic movements?', Planning Theory, 8, I40-65.

RYDIN, Y., LEE, M. and LOCK, S. J. (2015), 'Public engagement in decision-making on major wind energy projects', fournal of Environmental Law, 27, I39-50.

RYDIN, Y., NATARAJAN, L., LEE, M. and LOGK, S.J. (2018a), 'Black-boxing the evidence: planning regulation and major renewable energy infrastructure projects in England and Wales', Planning Theory \& Practice, 19, 218-34.

RYDIN, Y., NATARAJAN, L., LEE, M. and LOCK, S. J. (20I8b), 'Local voices on renewable energy projects: the performative role of the regulatory process for major offshore infrastructure in England and Wales', Local Environment, 23, 565-8I.

Schuler, U., GHoOcharoen, G., Elstner, P., NeEF, A., STAHr, K., ZAREi, M. and HERRMANN, L. (2006), 'Soil mapping for land-use planning in a karst area of N Thailand with due consideration of local knowledge', Journal of Plant Nutrition and Soil Science, r69, $444^{-52 .}$

SIMON, H. A. (1978), 'Rationality as process and as product of thought', The American Economic Review, 68, I-I6.

SMITH, R. W. (I973), 'A theoretical basis for participatory planning', Policy Sciences, 4, 275-95.

SONGSORE, E., BUZZELLI, M. and BAXTER,J. (2017), 'Understanding developer perspectives and experiences of wind energy development in Ontario', Environment and Planning C: Politics and Space, 36, doi: Io.II77/23996544I772 I93I. 
STEWART, D. W., SHAMDASAni, P. N. and ROOK, D. W. (2002), Focus Groups: Theory and Practice, Thousand Oaks, CA, Sage Publications.

SWYNGEDOUW, E., MOUlaERT, F. and RODRIGUEZ, A. (2002), 'Neoliberal urbanization in Europe: large-scale urban development projects and the new urban policy', Antipode, 34, $542-77$.

TAIT, M. (20I2), 'Building trust in planning professionals: understanding the contested legitimacy of a planning decision', Town Planning Review, 83, 597-6r8.

Talvitie, A. (20 I I), 'The problem of trust in planning', Planning Theory, II , 257-78.

TOKE, D. (2005), 'Explaining wind power planning outcomes: some findings from a study in England and Wales', Energy Policy, 33, I527-39.

TSO (THE STATIONERY OFFICE), (2008), Planning Act 2008, London, TSO.

UPHAM, P. and SHACKLEY, S. (2006), 'The case of a proposed 21.5 MWe biomass gasifier in Winkleigh, Devon: implications for governance of renewable energy planning', Energy Policy, 34, 216 $\mathrm{I}-72$.

WALKER, G. and DEVINE-WRIGHT, P. (2008), 'Community renewable energy: what should it mean?', Energy Policy, 36, 497-500.

WALKER, G., SENECAH, S. L. and DANIELS, S. E. (2006), 'From the forest to the river: citizens' views of stakeholder engagement', Human Ecology Review, I3, I93-202.

WARGENT, M. and PARKER, G. (2018), 'Re-imagining neighbourhood governance: the future of neighbourhood planning in England', Town Planning Review, 98, 379-402.

WENGER, E. (2010), 'Communities of practice and social learning systems: the career of a concept', in C. Blackmore (ed.), Social Learning Systems and Communities of Practice, London, Springer-Verlag, I79-98.

WESSELINK, A., PAAVOLA, J., FRITSCH, O. and RENN, O. (20I I), 'Rationales for public participation in environmental policy and governance: practitioners' perspectives', Environment and Planning A, 43, 2688-704.

YLI-PELKONEN, V. and KOHL, J. (2005), 'The role of local ecological knowledge in sustainable urban planning: perspectives from Finland', Sustainability: Science, Practice E尺 Policy, I, 3-14. 